\title{
THE ROLE OF PARENTAL INFLUENCES ON THE ECONOMIC SOCIALIZATION OF CHILDREN
}

\author{
Sabina Kołodziej, Katarzyna Lato, Magdalena Szymańska \\ Kozminski University, Warsaw, Poland \\ E-mail: skolodziej@alk.edu.pl, 24743@alk.edu.pl, 16914@alk.edu.pl
}

\begin{abstract}
Knowledge and understanding of basic economic concepts is crucial for the future orientation of children in a world of economy and influences taken in this sphere behaviors. Therefore, the aim of formal and informal economic education is to prepare young people to make independent and smart decisions regarding his or her financial resources. Nowadays, children earlier and earlier begin activity on the market, thus the economic knowledge role increases. Article presents two studies analyzing the relation between parents behaviors and children economic knowledge, understanding of market mechanisms and their decisions regarding money. Study 1 focused on parents informal education activities in the sphere of economics. The research covered a group of 100 respondents (50 pairs - parent and a child) and used questionnaires (separately for children and parents) on parents activity in the sphere of economic socialization. As a second part of the study children solved the Basic Economic Test (Walstad \& Robson, 1990) designed to measure the level of economic knowledge among school-aged children. The study 2 analyzed the relations between parents activity connected with economic socialization and children economic knowledge as well as behaviors related to saving, borrowing, lending and repayment of one's debt. In this study a group of 52 children took part and filled in a questionnaire on their economic knowledge and behaviors as well as their parents activities concerning economic socialization. Study 1 showed a positive correlation between parents informal education activity in the field of economics and the economic knowledge level of children. Study 2 showed higher levels of economic knowledge and more frequent attempts to earn money among children who receive pocket money. Results of both studies showed that the level of economic knowledge among children whose parents give them pocket money, explain economic issues and talk with children about planning household budget is significantly higher that among children who are not animated by parents. Moreover, parents activity in this field plays a vital role in shaping children's first economic activities.
\end{abstract}

Key words: children, economic education, economic knowledge, parents, pocket money.

\section{Introduction}

Nowadays, rapidly changing economic realities are challenging and forcing people to the continuous process of adaptation as well as to take advantage of emerging opportunities in the environment. Therefore, today's labor market emphasizes the need of flexibility of potential employees, expressed in their capacity to change the method, place, or nature of work. From this perspective, the pedagogical literature more often stresses the need for adequate professional training of future employees to prepare them for employers' requirements (Lewandowski, 2011; Maruszewska, 2011; Matuszak, 2012; Turska, 2013).

By analogy, a similar flexibility is increasingly required also in individual economic decisions taken by consumers in the rapidly changing market of goods and services. Technological development has changed not only the conditions and methods of work, but also has influenced significantly consumer behaviors, by increasing the range and medium of marketing 
Sabina Kołodziej, Katarzyna Lato, Magdalena Szymańska. The Role of Parental Influences on the Economic Socialization of Children

PROBLEMS

OF EDUCATION

IN THE $21^{\text {st }}$ CENTURY

Volume 58, 2014

100

messages' impact, product availability, as well as the rapidity of transactions. However, formal education acquired during adolescence, designed to prepare young people to effectively perform as an employee (and perhaps employer) in the future, rarely focuses on preparation for acting independently in the world of goods and services as a consumer.

A concept which refers to "the whole process by which a child will develop an understanding of the economic world is economic socialization. It concerns the acquisition of knowledge, skills, behavior, opinions, attitudes and representations, which are relevant to the economic world" (Roland-Levy, 1999, p.175). Thus, economic socialization is a process designed to equip children with the knowledge and skills needed for effective management of their financial resources in the future. This process takes place through formal and informal education. Informal education takes place mainly in the family, through everyday observations and experiences. Although this research topic is present in psychology consistently since the early 70's in the twentieth century, its relevance in recent years is rising again. This is mainly by increasing consumer activity among younger and younger children. According to research results, part of 4 years old children has their own money, while $40 \%$ at the age of 4-18 years regularly receives pocket money (Jasielska \& Maksymiuk, 2010). Another important fact is that children not only decide about allowances which they're spent mostly on snacks, toys and electronic gadgets, but they also determine the purchasing of many other products used in the household. Also, the availability of new media makes children earlier and earlier influenced by advertisements which have a high power of persuasion especially in the youngest group. Recent studies on economic socialization highlight the question of relevant activities aimed at preparing children to the modern economic realities (Meyer \& Anderson, 2000; Webley \& Nyhus, 2006; Jasielska \& Maksymiuk, 2010).

Studies in the field of economic socialization emphasize the close relationship with the cognitive development, particularly referring to the Piaget theory as the essential indicator of one's ability to understand economic concepts (Berti \& Bombi, 1988). Piaget describes cognitive development in four stages, which lead to understanding of surrounding reality and enable accommodation to it. According to Piaget, gaining new schemes of one's behavior take place thanks to the process of: 1) assimilation which means supplementing existing cognitive schemes for newly obtained information and 2) accommodation, i.e. modification of existing schemes due to newly collected information. As child grows, he undergoes from the stage of sensomotoric intelligence ( $0-2$ age), through the stage of preoperative intelligence (2-6 age) and specific operations (6-12 age) to the stage of formal operations (12-15 age). Formal operations stage allows a child to create a consistent system of knowledge.

Second psychological theory explaining the process of acquisition of economic knowledge and skills is the Bandura theory of social learning (Berti \& Bombi, 1988). It emphasizes the role of environment and received from it incentives on child future behavior. According to Bandura, process of learning depends on observations of behaviors effects made by children. If a specific behavior leads to positive effects, it will be understand as an award and will increase the probability of repeating the given behavior in the future. Similarly, penalty - that is negative effect - will minimize the probability of reenacting one's reaction.

Bandura emphasizes the role of "social models", i.e. persons important for child (e.g. parents, teachers, peers or heroes of fairy tales or films), whose impersonation does not require awarding or penalties, because observing them and repeating their behaviors is already an award for the child. In the process of economic socialization "the social model" role is mainly played by parents whose everyday financial behaviors are observed by their children.

Therefore, many authors claimed the important role of parents and their behavior on children's economic knowledge and skills (Lassare, 1996; Reitman \& Gross, 1997; Furnham, 1999; Webley \& Nyhus, 2006; Otto, 2009). However, it should be noted, that majority of those studies were conducted in the countries of Western Europe or in the United States, where the free market works much longer than in Poland or in other countries from the former Communist bloc. Moreover, there have been no similar studies in the last decade. 
Western European and American society, as a consequence, has a long tradition of preparing their children to cope with complete freedom of goods and services, while in countries from Central and Eastern Europe, including Poland, majority of today's parents gathered this knowledge during the ongoing socioeconomic changes. Moreover, in most cases, this process took place without any previous preparation, and very often meant the need to learn by trial and error method.

This relatively short process of acquiring knowledge relating to the economic realities of the market economy could translate into low scores achieved by the Poles in the financial literacy tests (Maison, 2013). Those tests examine the level of understanding of basic economic concepts and relationships as well as knowledge of current economic indicators (such as inflation, unemployment, interest rates). Consequence of the lack of basic financial knowledge can be expressed by taking the wrong financial decisions, leading to excessive debt in the future.

\section{Problem of Research}

In the light of these findings, an important issue is the question of parental interaction in the field of informal economic education taking place in the countries of the former communist bloc. Previous studies on economic socialization have analyzed the impact of parents coming from countries with developed market economy, who possessed a rich baggage of experience in this field and could share it with their children. The situation of the parents of the former communist countries is different: in childhood they were surrounded by completely different socio - economic conditions and they adopted the principles of the market economy with the transformation, mostly in adulthood. The centrally planned economy meant that parents did not talk to their children about different alternatives to choose from, because they did not exist. Therefore, those parents may be not equipped - like their counterparts from Western Europe or United States - in patterns that help introduce their children into the world of economy. In addition, the results which showed a relatively low level of economic knowledge among adults suggest another potential factor that could weaken the intergenerational transmission - it might be difficult for parents to transfer knowledge when they do not have it at a sufficient rate.

\section{Research Focus}

The aim of conducted studies was to describe informal educational activities undertaken by parents in the economic sphere as well as analyze the impact of parents behaviors on children economic knowledge and understanding of market mechanisms and on their decisions regarding money. The article refers results of two studies. The first study focused on parents involvement associated with transferring children knowledge and helping them understand the economic world. The second study analyzed the relations between one aspect of informal economic education - paying regular pocket money to children - and children economic knowledge and behaviors related to money (consumption and earning).

Based on the results of previous studies, the following hypotheses were formulated:

H.1: There is a positive relationship between the level of economic knowledge of children and parents' activity in this area.

H.2: Children who receive a pocket money have a higher economic knowledge that children who do not receive pocket money.

H.3: Children who receive pocket money differ in economic behaviors from children who do not receive pocket money.

The basis for these hypotheses was an assumption that the parents willingness to undertake economic topics with children - even when their own level of knowledge is insufficient proves their great openness in this regard, which will translate into a higher level of knowledge and skills of their children. 
Sabina Kołodziej, Katarzyna Lato, Magdalena Szymańska. The Role of Parental Influences on the Economic Socialization of Children

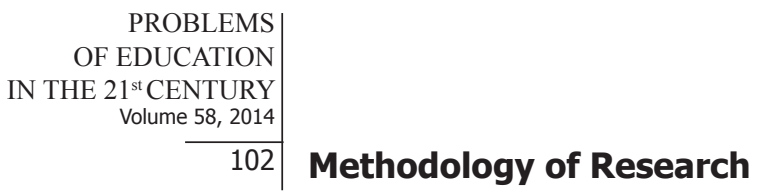

General Background of Research

In order to verify the hypothesis 1 a survey was conducted among a group of parents and children. The study took the form of the questionnaire, parents and children separately answered the questions on transferring economic knowledge. The hypothesis 2 and 3 were verified in the second study where the analysis of the relation between parents economic socialization activity, especially the regular payment of pocket money to children, and children economic knowledge and behaviors was conducted.

\section{Sample of Research}

The first study involved 100 people, forming a pair of parent - child. The majority of the parents were mothers (97\%), which is in accordance not only with the majority of previous studies of this range, but also with the findings, that mother plays a greater role in shaping economic behavior of children. The majority of parents (37 people) graduated from secondary school, while the rest had elementary (5) or higher (8) education. Exactly half of the respondents resided in rural areas, and the second half came from medium-sized cities (20-100 thousand of inhabitants). Children participating in this study formed two age groups: 11 and 15 years, which allowed to trace the aspect of the developmental increase in the level of economic knowledge.

The sample of the second study was 52 children in the age between 8 and 13 years. Among the respondents was $44 \%$ girls and $56 \%$ boys from the Polish capital. At the beginning a pilot study was carried out to examine whether there are any ambiguities in the survey. The pilot study was conducted among children aged 8-9 years, who potentially could have the biggest problems with filling in the questionnaire. Both studies took place in 2012.

\section{Instrument and Procedures}

In the first study a method of diagnostic survey which focused on parents informal education activity in the sphere of economics was used. Questions addressed to the parents concerned the provision of pocket money, control of children expenditures, enabling them to talk about the economic issues of the family, saving, debts, presenting the plan of monthly expenses. Sample question: "Does your child participate in discussions on economic issues of family? a) child is not a witness of such talks; b) listens passively; c) participates actively in the discussion; d) his opinion is taken into account when deciding". The study also analyzed the children perception of parent's activity in the field of economic socialization. Sample question: "Do you talk to parents about saving? a) yes, often; b) occasionally; c) rather not, because parents do not take such topics; d) definitely not".

In order to diagnose the level of economic knowledge among children, the "Basic Economic Test" (BET) was used (Walstad \& Robson, 1990). BET consists of 29 single choice questions relating to the basic economic concepts and relations. Sample question: "When the United States sell Saudi Arabia grain, buying oil in return: a) both countries are losing; b) the two countries are gaining; c) the United States gain, Saudi Arabia loses; d) gains Saudi Arabia, the United States lose".

A questionnaire which was used in the second study consisted of two parts: first part concerned children economic behaviour, such as spending money, earning and savings. Sample question: "What are you buying from your pocket money?" Respondents task was to select from a list of goods (e.g. sweets, snacks, drinks, newsletters, comics, books, CDs, DVDs, computer games, toys, tickets, clothing) those products which they usually buy. The second part of the questionnaire was devoted to respondent's parents activity regarding economic socialization. 
Sample question: "Did your parents not allow you to buy something from your pocket money? a) It has never happen, b) It happened a few times c) It happens sometimes, but not always, d) It happens every time when we do shopping together".

The last part of the questionnaire included questions examining the level of economic knowledge, formulated on the model of Basic Economic Test used in the first study. Sample question: "How much money must be returned to the bank, if you borrow 100 zloty? a) less b) the same c) more d) I do not know".

\section{Data Analysis}

Analysis of data obtained in studies aimed at empirical verification of formulated hypotheses. The Shapiro - Wilk test let conclude that the data distribution is close to a normal distribution, which allowed the use of parametric tests. With respect to the hypothesis 1 , concerning the relationship between the variables, the r-Pearson's correlation was measured, while in case of hypotheses 2 and 3, speaking about the differences between groups, the Student's t-test was used.

\section{Results of Research}

The questionnaire in study 1 covered, in particular, four aspects of parents activity: paying regular pocket money to children, controlling their expenditures, joint planning of the household budget, talking with children about the economy, savings and indebtedness. The analysis of the answers given by the children and parents in questionnaires on transferring of economic knowledge by parents indicated high convergence. Relatively the most frequent activity among parents is connected with the control of children's expenditures $-70 \%$ of parents show interest in their children's expenses, discreetly suggest on what children should spend their money. The vast smaller number of parents, however, pay a regular pocket money to children - only $34 \%$ of respondents. The amount of the allowance is not fixed, but depends on the current financial situation of the family.

With regard to undertake in the presence of the children topics related to the economic situation of the family, results showed that only $16 \%$ of children actively participate in such talks. With the same frequency $(30 \%)$ respondents marked that children are listening passively to conversations of their parents or are not witnesses to these conversations. In one-quarter of the surveyed families opinions of children are not taken into account when making any decision concerning household budget. The majority of parents ( $82 \%$ ) also responded that the child does not take part in the joint planning of expenditures which has a great importance in the process of economic socialization. In this context, an interesting result is the fact that only $18 \%$ of parents declared talks with children on savings, while more than a half (56\%) raises the topic of debts and the mechanism of settling financial liabilities.

Results of the Basic Economic Test showed that the test group of children is characterized by a low level of knowledge (mean 16.11 for 29 points possible) - most of the questions, both on definitional issues, as well as economic relations, were very difficult for the children.

In order to verify the hypothesis 1 indicating that there is a positive relationship between the level of economic knowledge of children and parents' activity in this area, the r-Pearson correlation was conducted. For this purpose, based on the answers given by the parents, an indicator of parents activity in the field of informal economic education was created, which reached values in the range 0-3. This indicator has been correlated with the level of economic knowledge of children, as shown in the following table. 
Sabina Kołodziej, Katarzyna Lato, Magdalena Szymańska. The Role of Parental Influences on the Economic Socialization of Children

PROBLEMS

OF EDUCATION

IN THE $21^{\text {st }}$ CENTURY

Volume 58,2014

104

Table 1. R-Pearson correlation between parent activity in economic socialization and level of children economic knowledge.

\begin{tabular}{lll}
\hline & & $\begin{array}{l}\text { Level of children economic } \\
\text { knowledge }\end{array}$ \\
\hline \multirow{3}{*}{ Parent activity in economic socialization } & r-Pearson & 0.36 \\
\cline { 2 - 3 } & Significance & 0.01 \\
\cline { 2 - 3 } & $\mathrm{N}$ & 50 \\
\hline
\end{tabular}

As it can be seen in the table, there was a statistically significant positive relationship between the activity of parents in the field of economic socialization and the level of economic knowledge of their children, which is consistent with the assumption of hypothesis 1.

Results of the study 1 showed the important role of parents informal education activities in transferring children economic knowledge, but because of the small number of parents who pay their children pocket money or undertake other activities in the economics, the in-depth analysis could not be carried. In order to verify the hypothesis 2 and 3 a study on the relation between parents economic socialization activity, especially the regular payment of pocket money to children, and children economic knowledge and behaviors was conducted.

According to the answers obtained in the studied group, almost half of children (48\%) received a regular allowance from their parents. Respondents said that the most frequently they got pocket money once a month $(60 \%)$, rarely - just under one third - responded that parents gave the money once a week. The amount of pocket money varied, but most often contained in an amount between 3 and 6 euros. Outside allowance, children received money from their parents and other family members (grandparents, aunts, uncles) as a gift, prize or payment for work performed at home (e.g. car wash). According to our results, the most common purchases are sweets, clothes, cosmetics and computer games. Children admitted that although have their own money and make purchases alone, parents monitored their behavior - half of parents did it more than once a month, the other half less.

The questionnaire included also questions about commercial work undertaken by children. Among the respondents, only twenty percent admitted that they earn money, usually several times a month, sometimes less. Activities with the higher frequency were connected with the minor domestic help: snow removal, mowing the lawn, cleaning the house.

The second hypothesis formulated in the study assumed that children who receive a pocket money have a higher economic knowledge that children who do not receive regular money from their parents. In order to verify the assumption the $t$ test between two distinguished groups was conducted as it is shown in Table 2. The results of the conducted test showed that children whose parents give them regular pocket money have a significantly higher level of economic knowledge than children who do not receive pocket money.

Table 2. Difference in the level of economic knowledge between children with and without pocket money.

\begin{tabular}{lll}
\hline & Children with pocket money & Children without pocket money \\
\hline Mean & 6.39 & 5.37 \\
\hline Stand. dev. & 1.50 & 1.44 \\
\hline T test & 2.55 & \\
\hline Significance & 0.05 & \\
\hline
\end{tabular}


The last formulated hypothesis assumed differences in economic behaviors among children from distinguished groups. The designed questionnaire analyzed three types of economic behavior that can be undertaken by children: spending, savings and earning.

For obvious reasons, children receiving regular pocket money were more active consumers than the children who do not receive money from their parents, buying more frequently and a wider range of goods. A detailed analysis of the frequency of their purchases, made using chi-square test showed that children receiving pocket money often make small purchases (e.g. drinks), while the second group of respondents - receiving money irregularly, in the form of gifts from the closest family buys electronic equipment or computers. It can be assumed that they are not shopping alone, but with their parents. Analysis of the other kind of economic behavior - savings - did not showed statistically significant differences between two groups. Last analyzed aspect concerned earning behaviors among children. Results showed that children did not differ in terms of the type of work they performed. Majority of them when earning money make simple physical work like car washing, house cleaning or some of them sometimes do babysitting. What was interested that the frequency of those work was significantly differ between those two groups: children who receive pocket money more often attempted to make money $(\mathrm{t}=2.18, \mathrm{df}=22, \mathrm{p}>0.05)$.

\section{Discussion}

Research described in the article have been taken to investigate whether Polish parents, despite the lack of economic socialization patterns, talk with their children on economic issues, and try to prepare them through other actions to make independent financial decisions in the future. The results of the first study showed that parents declare discussing economic issues with children, but in practice very often it means the control of children's expenses. According to the result, only $16 \%$ of children take part in discussions on economic issues of their family while the rest can passively listen to parents decisions or are not even witnesses of dialogues on such topics. Moreover, parents from the first study relatively rarely give children poket money which is one of the best method of teaching money management.

Despite this, the results of the analyzes showed that even a slight parents impact on socialization, indicating - as assumed - not the economic knowledge of parents, but their cognitive openness in this regard, had a positive impact on the level of economic knowledge to their children. According to the obtained result of r-Pearson correlation, the activity of the parents in terms of economic socialization has a significant positive relation with the level of children economic knowledge, which allowed to confirm the first of the accepted hypotheses.

However, the average scores (16.11) in the Basic Economic Test gained by the group of Polish children were lower than the results of their peers in the United States (Walstad \& Robson, 1990). Descriptive statistics for various groups within the norming sample in United States showed that the mean was between 18.20 and 19.70. It should be noted that the quoted results refer to tests carried out on large, representative samples, while study described in the article was conducted on a relatively small sample. Still, the trend of getting low scores on tests of economic knowledge by Polish children was confirmed in other studies (Kołodziej, 2012).

The second of the referred study was to answer questions about the relationship between receiving regular pocket money, which is considered as a very important element of economic socialization, and the level of economic knowledge and behaviors undertaken in this area by children. In the examined group, almost half (48\%) of children received pocket money, which could be related to the fact that children from large cities receive pocket money more often in comparison to children living in rural or small towns (IPSOS, 2005). However, it should be noted, that according to children answers, they were paid pocket money mostly per month, which for relatively young children (8-13) might be too long time horizon and cause difficulties in proper planning of expenditure. This rule probably results from two factors - in Poland, unlike in Western Europe or the United States, the vast majority of remuneration is paid monthly. Taking 
Sabina Kołodziej, Katarzyna Lato, Magdalena Szymańska. The Role of Parental Influences on the Economic Socialization of Children

PROBLEMS

OF EDUCATION

IN THE $21^{\text {st }}$ CENTURY Volume 58,2014

106

into account parents claimes that the pocket money is not fixed but the amount depends on the financial situation of the family, it can be assumed that the decision to pay allowance is made after receiving salary and paying bills. The second factor which has already been highlighted in the introduction, is the lack of economic socialization patterns among parents.

However, analysis conducted on the results from the second study demonstrated a significant positive relation between allowance paid to children and their level of economic knowledge, which was consistent with the hypothesis 2 and findings of previous studies (Berti \& Bombi, 1988, Roland-Levy, 2004). It should be noted that the group of children receiving pocket money consisted of only those who reported receiving money for their own needs on a regular basis. The results are therefore consistent with the previous findings indicating that regularity is one of the features of a pocket money, which determines its positive impact on the socialization (Roland-Levy, 2004).

The analysis of results allowed also to characterize the economic behavior of distinguished groups of children. Receiving regular pocket money allows children present as an actor in exchange transactions more often, which contributes to the accumulation of experience by children. An indirect confirmation of this assumption comes from the categories of goods children buy from their own resources - children receiving pocket money often indicated products such as beverages, so cheap, frequently purchased products. Children in the second group, receiving money occasionally, in the form of gifts declared that they buy electronic products, so goods rarely buy, predominantly least accompanied by their parents.

There were no significant differences regarding children's savings behavior. This could be due to the fact that children generally declared saving money from gifts, and spending those from allowances. However, this result should be taken into account when planning further studies of this subject, as investigation of possible differences in this area requires proper construction of the questionnaire.

Statistically significant difference was obtained in questions relating to earning behavior. Children who received pocket money more often seek ways to earn money in comparison with children who were not given pocket money. This result allows for a partial confirmation of the hypothesis 3 . And above all, however, it is very important from the perspective of shaping parents' socialization activity because it shows that enabling children economic activity through giving them pocket money, can contribute to a more active approach of children relating financial matters.

The study was an attempt to fill the gap in research on the process of transfer of knowledge and economic skills to children. However, evaluation of the results should take into account their limitations associated mainly with the number of respondents. Therefore, these results should be treated as preliminary findings, demanding confirmation on a large, representative sample. However, their consistency with the available literature suggests that the described relationships will be confirmed.

\section{Conclusions}

Preparing children for independent and efficient acting in the world of economy is an extremely important developmental task of childhood. The process of acquiring economic knowledge and skills is made both by observing the behaviour of parents and other people important to the child as well as gaining his/ her own experiences in this field. Therefore, analysis of the role of parents activity in economic socialization should take into account their level of knowledge and skills which they transmit to children.

Results of conducted studies showed that economic socialization refers to the behavior and thinking patterns shaped in the community. History provided evidences that change in human patterns is slow and results from the broader transformation which take place in the social - economic reality. These conclusions highlight the importance of proper education of not only children, but also adults who become teachers of their children. 
Sabina Kołodziej, Katarzyna Lato, Magdalena Szymańska. The Role of Parental Influences on the Economic Socialization of Children

\section{References}

Berti, A. E, Bombi, A. S. (1988). The child's construction of economics. Cambridge: Cambridge University Press.

Furnham, A. (1999). Economic socialization: A study of adults' perceptions and uses of allowances (pocket money) to educate children. British Journal of Developmental Psychology, 17, 585-604.

IPSOS (2005). Kieszonkowe naszych dzieci. Warszawa: IPSOS. Retrieved from http://www.ipsos.pl/ kieszonkowe-dzieci-2005.

Jasielska A., Maksymiuk, R. A. (2010). Dorośli reklamuja, dzieci kupują. Kindermarketing i psychologia. Warsaw: Wydawnictwo Naukowe Scholar.

Kołodziej, S. (2012). How do Polish children understand economic concepts? General and Professional Education, 1, 15-22.

Lassarre, D. (1996). Consumer education in French families and schools. In: Economic socialization: The economic beliefs and behaviours of young people. Ed.: P. Lunt \& A. Furnham. Cheltenham: Edward Elgar Publishing Limited.

Lewandowski, R. (2011). Reflections on vocational education in Poland. General and Professional Education, 2, 28-32.

Maison, D. (2013). Polak w świecie finansów. Warsaw: Wydawnictwo Naukowe PWN.

Maruszewska, E. W. (2011). Ethical education of accounting students in Poland. General and Professional Education, 1, 26-30.

Matuszak, Z. (2012). Do teaching methods at a technical university allow students to acquire competencies? General and Professional Education, 3, 12-19.

Meyer, D. J. C., Anderson, H. C. (2000). Preadolescents and apparel purchasing: Conformity to parents and peers in the consumer socialization process. Journal of Social Behavior and Personality, 15, 243-257.

Otto, A. M. C. (2009). The economic psychology of adolescent saving. Unpublished Doctoral Dissertation. Exeter: University of Exeter.

Reitman, D., Gross, A. M. (1997). The relation of maternal child-rearing attitudes to delay of gratification among boys. Child Study Journal, 27, 279-302.

Roland-Levy, Ch. (1999). Economic socialization. In: The Elgar Companion to Consumer Research and Economic Psychology. Ed.: P.E. Earl \& S. Kemp. Cheltenham: Edward Elgar Publishing Limited.

Turska, E. (2013). Who are Polish future educators? Selected aspects of social identifications. Problems of Education in the $21^{\text {st }}$ Century, 56, 150-157.

Walstad, W. B., Robson, D. (1990). Basic Economic Test, Second Edition: Examiner's Manual. New York: Joint Council of Economic Education.

Webley, P., Nyhus, E. K. (2006). Parents' influence on children's future orientation and saving. Journal of Economic Psychology, 27, 140-164.

Advised by Ewa Wanda Maruszewska, University of Economics in Katowice, Poland

Received: January 30, 2014

Accepted: March 21, 2014

\begin{tabular}{|ll|}
\hline Sabina Kołodziej & PhD, Assistant Professor, Kozminski University, 57/59 Jagiellonska Street, \\
& $\begin{array}{l}\text { 03-301 Warsaw, Poland. } \\
\text { E-mail: skolodziej@alk.edu.pl }\end{array}$ \\
\hline \multirow{2}{*}{ Katarzyna Lato } & Student, Kozminski University, 57/59 Jagiellonska Street, 03-301 Warsaw, \\
& $\begin{array}{l}\text { Poland. } \\
\text { E-mail: 16914@alk.edu.pl }\end{array}$ \\
\hline \multirow{2}{*}{ Magdalena Szymańska } & $\begin{array}{l}\text { Student, Kozminski University, 57/59 Jagiellonska Street, 03-301 Warsaw, } \\
\text { Poland. } \\
\end{array}$ \\
& E-mail: 24743@alk.edu.pl
\end{tabular}

